\title{
The Independent Functions of the Two Heads of the Lateral Pterygoid Muscle '
}

\author{
JAMES A. MCNAMARA, JR.
}

Department of Anatomy and Center for Human Growth and Development, The University of Michigan, Ann Arbor, Michigan 48104

\begin{abstract}
Investigations on the role of the lateral pterygoid muscle in mandibular movements have been limited due to difficulties in obtaining consistent neuromuscular recordings in human subjects. The rhesus monkey was used as a substitute experimental animal. Thirty-three Macaca mulatta were monitored in 113 electromyographic recording sessions. Two distinct functional patterns were identified from the region of the lateral pterygoid muscle, depending upon the location of the electrodes within this muscle. Through anatomical dissection of areas of electrode placement in 12 animals, the two patterns of activity were related to the inferior and superior heads of the lateral pterygoid muscle. The inferior head acted synergistically with the suprahyoid muscle group in opening movements of the mandible. No activity was noted in closing movements, or in swallowing. In contrast, the superior head was not active during opening movements. Electromyographic activity of the superior head, antagonistic to the suprahyoid muscles, was observed during such closing movements as chewing and clenching of the teeth and during deglutition. The superior head presumably positioned or stabilized the condylar head and disc against the articular eminence during closing movements of the mandible, while the inferior head assisted in the translation of the condylar head downward, anteriorly, and contralaterally during opening movements. Thus, the two heads of the lateral pterygoid can be considered as two functionally distinct muscles.
\end{abstract}

The role of the lateral pterygoid in mandibular movement has historically been one of the most difficult to determine of all masticatory muscle functions. The positions of the lateral pterygoid muscle within the infratemporal fossa has hampered human electromyographic studies because electrode placement frequently produced pain and regional hematomas (Carlsöö, '52; Ekholm and Siirilä, '60; Griffin and Munro, '69).

The rhesus monkey (Macaca mulatta) offers a substitute experimental animal. However, specific differences exist in the anatomy of the temporomandibular joint in man and the rhesus monkey. The flatter articular eminence, shallower glenoid fossa and larger postglenoid spine (fig. 1) have been noted in the rhesus monkey by previous workers (Parsons, 1899; Zielinski, '65, and Zimmermann, '71). Angel ('48) has suggested that the relative flat- ness of the articular eminence and the position of the pterygoid plates indicate a more horizontal pull by the lateral pterygoid in the monkey than in man. Schumacher ('61) and Grant ('73b) have demonstrated that orientation of the two heads of the lateral pterygoid in the monkey is similar to that in man, but that they function at less oblique angles. In man, a more oblique downward pull by the inferior head and a more oblique upward pull by the superior head is observed (Sicher, '60). However, in both man and the rhesus monkey, fibers from the superior head are attached to the articular disc and capsule as well as to the condylar head (fig. 2).

The purpose of this study was to monitor and describe the functions of the lateral pterygoid muscle in the rhesus monkey.

1 This research was supported in part by United States public Health Service grants $\mathrm{HD}-02272$ and DE-03610. 


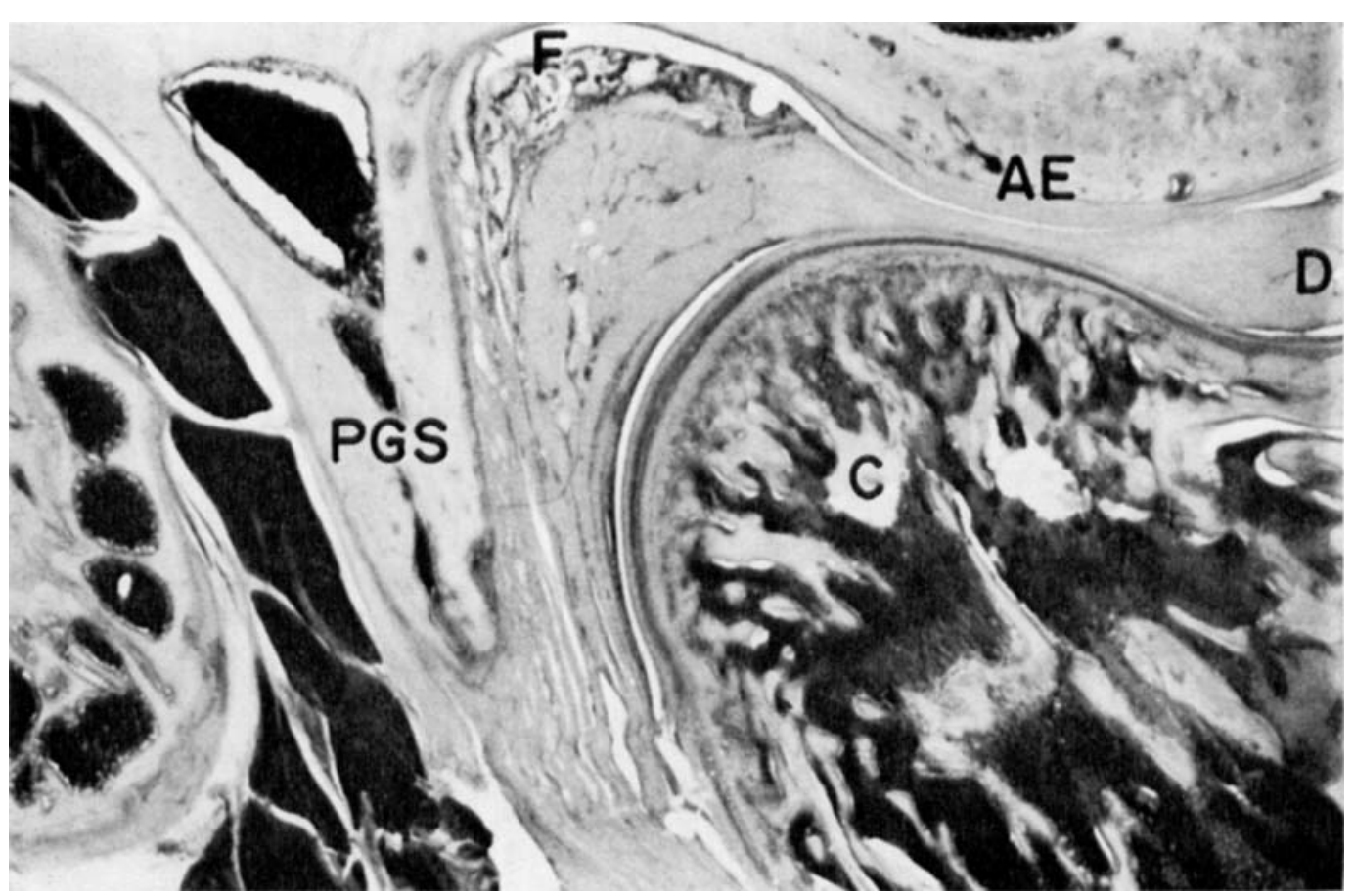

Fig. 1 Photomicrograph of a sagittal section of the temporomandibular joint. PGS, postglenoid spine; $C$, mandibular condyle; $D$, articular disc; $\mathrm{AE}$, articular eminence; $\mathrm{F}$, superior portion of the glenoid fossa. Hematoxylin and eosin. $\times 8$.

\section{MATERIALS AND METHODS}

Thirty-three Macaca mulatta, age six months to eight years, were monitored in 113 electromyographic recording sessions, consisting of one to two and one-half hours each. Initially, the animal was anesthetized by an injection of $6-10 \mathrm{mg} / \mathrm{kg}$ of Ketamine $\mathrm{HCl}$, a short-acting, dissociative anesthetic which has only a minor and transient effect upon the neuromusculature (McNamara and Kuroda, '71; Kuroda and McNamara, '72).

The anesthetized monkey was then placed in a sound-proof, electrically shielded chamber and chaired in a primate restraining device especially designed for electromyographic procedures (McNamara, '73). The head of the animal was oriented in a fixed position by means of a Plexiglas headholder to allow for normal jaw function in an unanesthetized condition.

The approach to the lateral pterygoid muscle was made extra-orally through the sigmoid notch of the mandible using two $25 \mathrm{~mm}$ Teflon insulated bipolar needle electrodes, 1-3 $\mathrm{mm}$ apart. In addition, pairs of $8 \mathrm{~mm}$ bipolar platinum electrodes were inserted aseptically into the anterior temporal, posterior temporal, anterior border of the superficial head of the masseter, superior portion of orbicularis oris, and the suprahyoid group of muscles including the anterior digastric, mylohyoid and geniohyoid muscles (fig. 3 ). The latter three muscles were regarded as a single muscle group because of the difficulty in separating them anatomically during positioning of electrodes. The anterior heads of the two digastric muscles in the rhesus monkey are not separated into two discrete bellies, as is typical in man. Rather, the anterior heads fuse at the midline and, in addition, often blend with fibers of the mylohyoid muscle (Bosma, '56; Howell and Straus, '69). All recordings were taken from the musculature on the left side. Electromyographic activity was recorded on Kodak Linagraph direct print paper using a Beckman Type $\mathbf{R}$ Dynograph amplifier and a Honeywell Model 1108 Visicorder. 


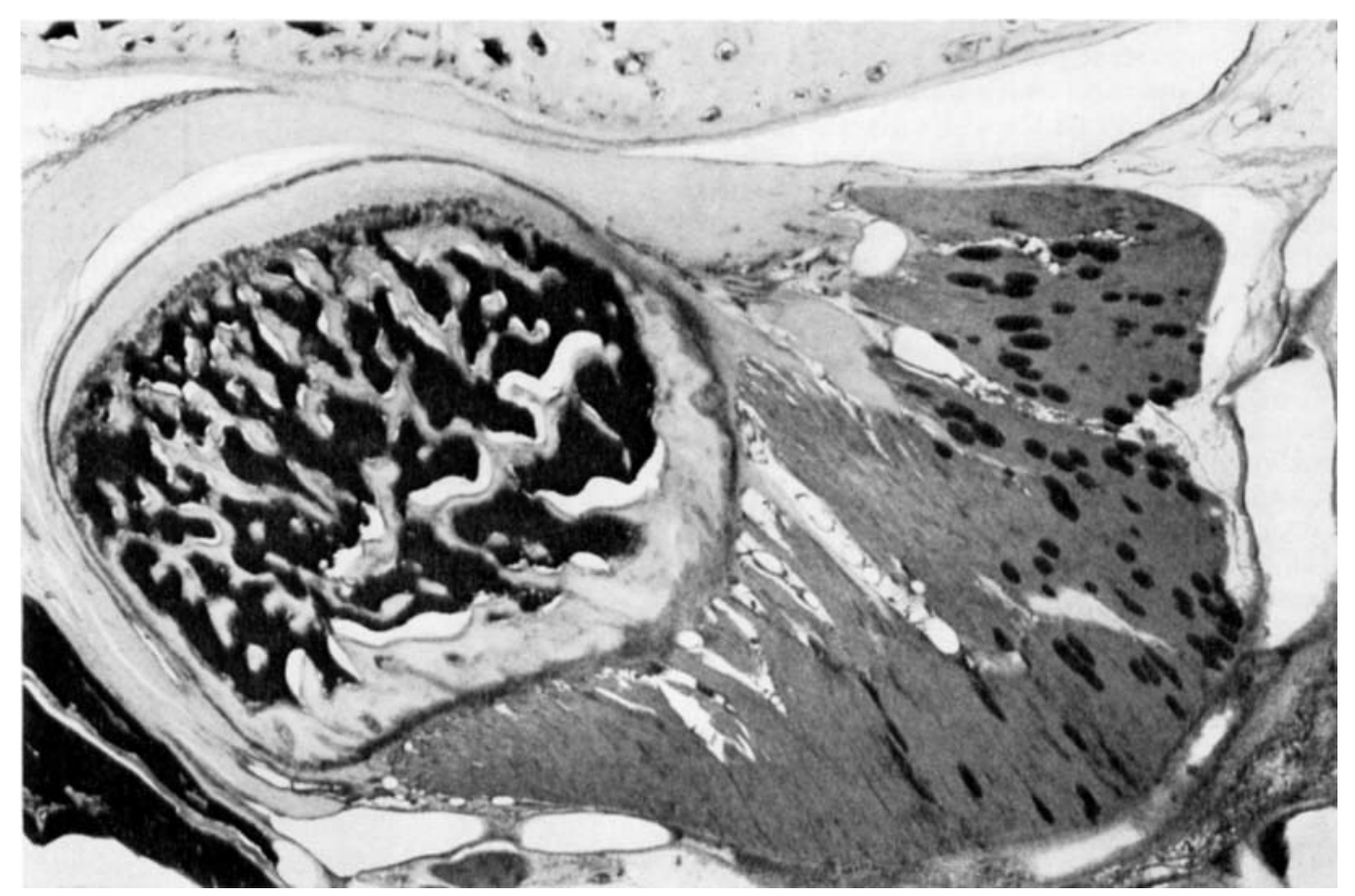

Fig. 2 Photomicrograph of a medial sagittal section of the attachment of the lateral pterygoid muscle into the anticular disc, joint capsule, and mandibular condyle. Hematoxylin and eosin. $\times 8$.

After verification of electrode placement, the animal was left isolated in the soundproof room for a minimum of 30 additional minutes to allow for complete recovery from the anesthetic. After this time, recordings of posture, oral reflexes, and random jaw movements were initiated while the animal was still in isolation. Reflex salivary swallows were recorded at this time. Later, the investigator entered the sound-proof room and generated water swallows and subsequent clearing swallows through the administration of $0.5 \mathrm{ml}$ tap-water by a syringe into the animal's mouth. Chewing was elicited by feeding the animal small chunks of sugar and bits of apple.

\section{OBSERVATIONS}

Initially no attempt was made to differentiate between the functions of the two heads of the lateral pterygoid muscle. However, during the recording sessions, three patterns of muscle activity were observed in the region of the lateral ptery- goid muscle. Sometimes pattern A was recorded, sometimes pattern B was recorded, and in a few instances a third pattern of activity was observed. It was soon obvious that the latter pattern represented a superimposition of pattern $A$ and pattern $B$ in the electromyographic records. The occurrence of each pattern of lateral pterygoid muscle activity depended upon the specific location of the pair of electrodes within the muscle. The location of electrode placement in 12 animals was examined through anatomical dissection and the two patterns of activity (patterns A and B) were related to the inferior and superior heads of the lateral pterygoid muscle, respectively. A drop of India ink was injected at the placement site of electrode tips, the animal was sacrificed immediately, these areas were examined, and the precise location of the electrodes within the muscle noted.

Pattern A (the inferior head). The lateral pterygoid muscle acted synergistically with the suprahyoid muscle group in 
opening movements of the mandible (figs. 4,5 ). The lateral pterygoid did not appear to initiate opening movements because the onset of activity in the suprahyoid usually preceded lateral pterygoid firings. However, the duration of suprahyoid activity before the initiation of lateral pterygoid function varied, ranging from 25-350 msec. The lateral pterygoid muscle was never active during the closing movements of the mandible, such as clenching and the closing phase of mastication, nor did it function in salivary, water, or masticatory swallows (fig. 5).

Anatomical dissection confirmed that pattern A originated from the inferior head of the lateral pterygoid muscle. This head presumably assisted in the translation of the condylar head downward, anteriorly, and contralaterally during opening movements of the mandible.

Pattern B (the superior head). This pattern of activity was distinctly different from that of pattern A. The firings of pattern $B$ occurred during a different phase of mandibular movement than did those of the suprahyoid musculature and thus no activity was recorded in the superior head of the lateral pterygoid during opening movements of the mandible. Discharges from the superior head were observed during closing movements (figs. 4, 6). The onset of lateral pterygoid function was usually concurrent with that of the elevator musculature during the closing phase of mastication and during clenching of teeth.

The superior head of the lateral ptery-

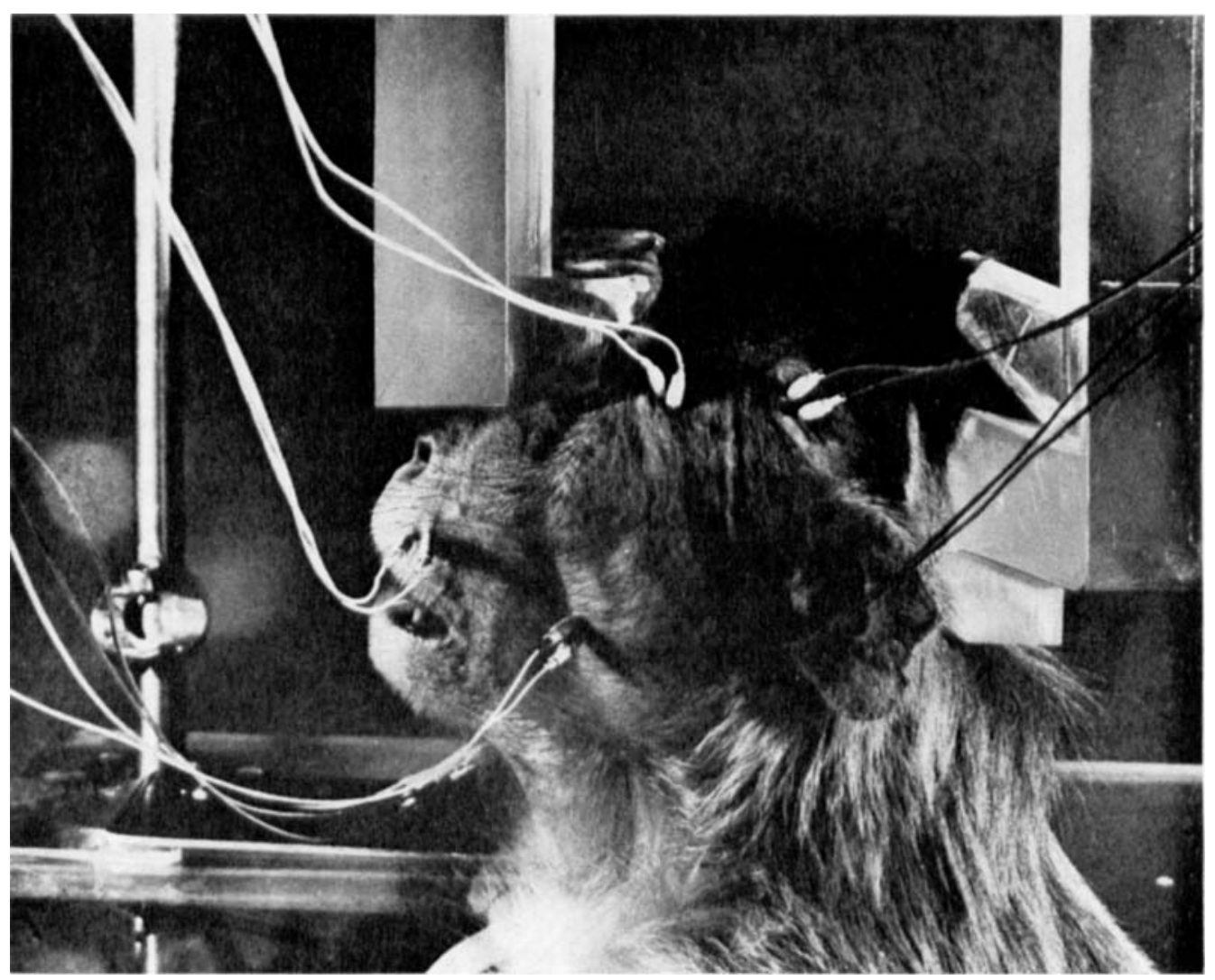

Fig. 3 Animal positioned in head-holder. Needle electrodes are in the anterior and posterior portions of the temporal muscle, the anterior portion of the superficial head of the masseter muscle, the orbicularis oris muscle, the lateral pterygoid muscle and the suprahyoid muscle group. 

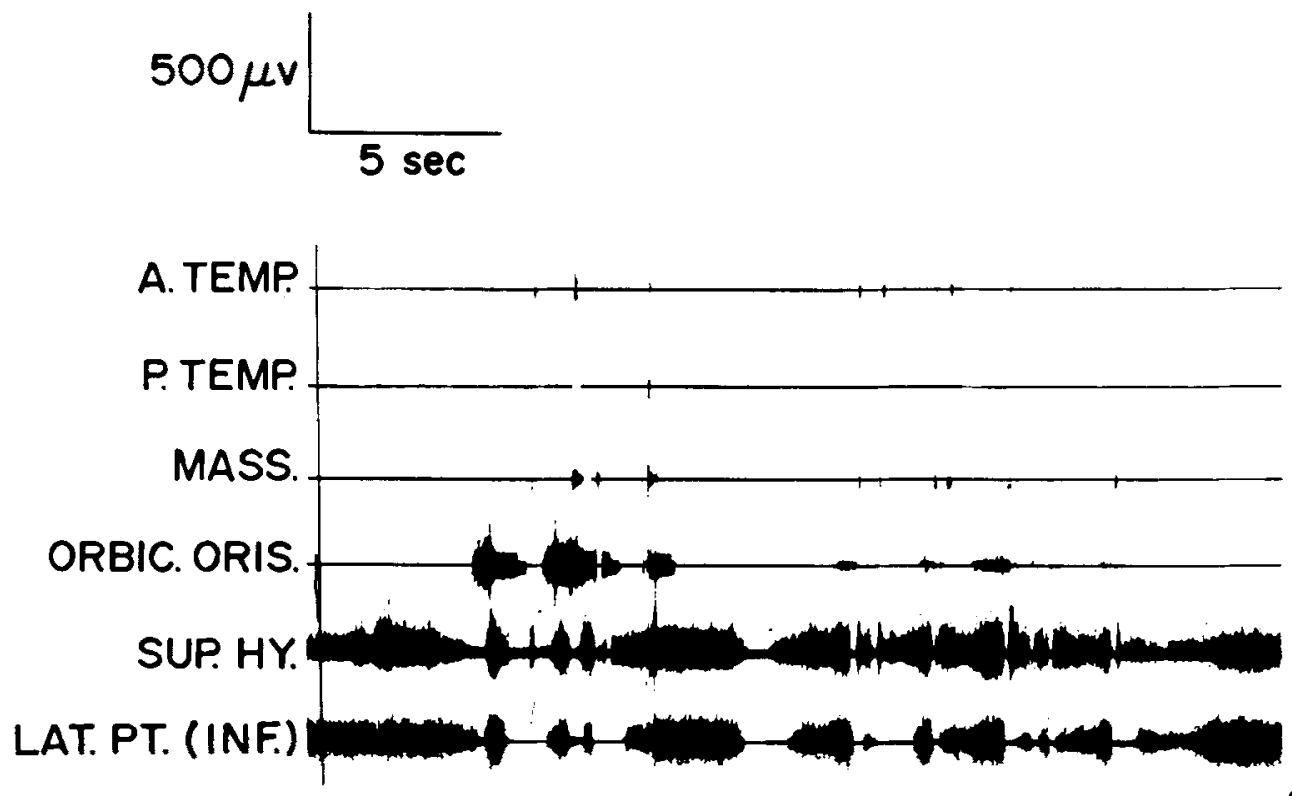

A. TEMP

P. TEMP.

MASS.

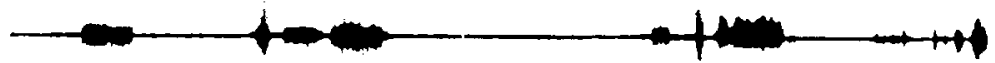

ORBIC. ORIS.

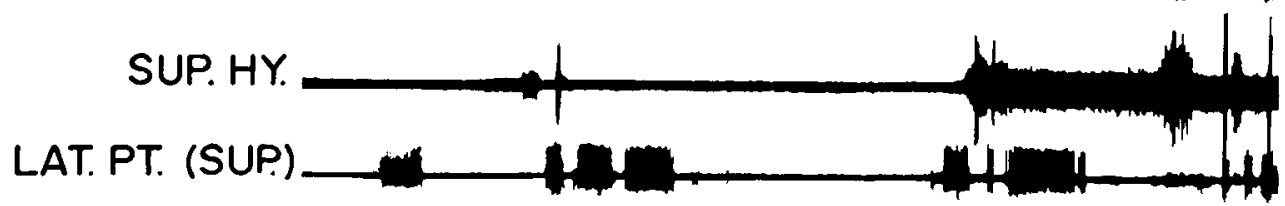

(b)

Fig. 4 Electromyographic recordings of the activity of the lateral pterygoid muscle during random jaw movement. (a) The activity of the inferior head (Pattern A) was usually associated with suprahyoid function during opening movements of the mandible and was antagonistic to the elevator muscles. (b) The superior head (Pattern B) acted synergistically with the masseter and temporal musculature during closing movements of the mandible. A. Temp., anterior portion of the temporal muscle; P. Temp., posterior portion of the temporal muscle; Mass., anterior portion of the superior head of the masseter muscle. Orbic. oris, superior portion of orbicularis oris; Sup. Hy., suprahyoid muscle group; Lat. Pt. (Sup.), superior head of the lateral pterygoid muscle; Lat. Pt. (Inf.), inferior head of the lateral pterygoid muscle. Recording speed $5 \mathrm{~mm} / \mathrm{sec}$.

goid muscle was also active during swallowing, but the onset and duration of this activity varied. The superior head usually fired concurrently with suprahyoid muscu- lature in a well circumscribed burst of activity for $250-350 \mathrm{msec}$ in swallows with little or no elevator function. In four animals the onset of lateral pterygoid activ- 


\section{$500 \mu v \mid \frac{}{500 \mathrm{msec}}$}

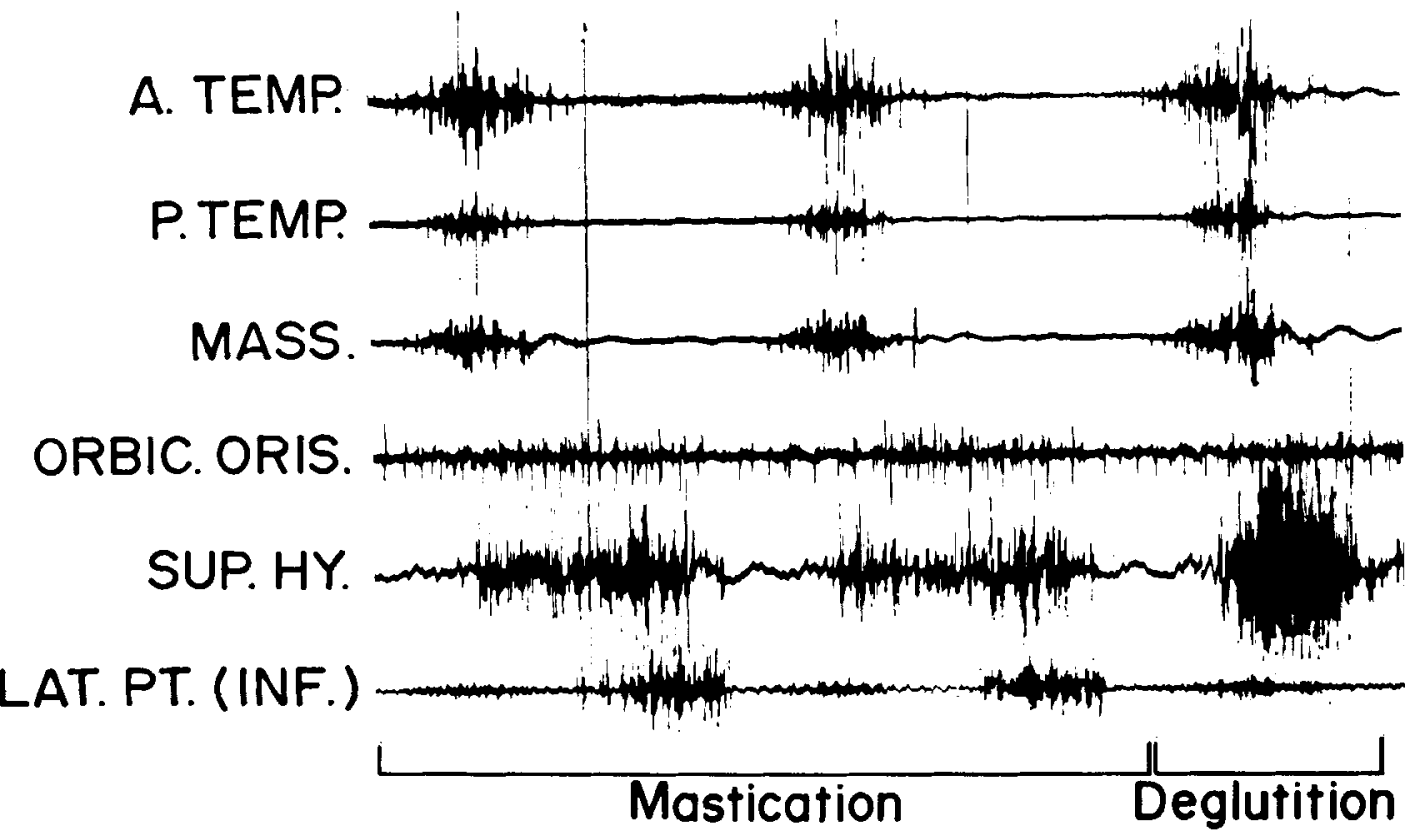

Fig. 5 Electromyognaphic recordings of the activity of the inferior head of the lateral pterygoid muscle during mastication and deglutition. Recording speed $100 \mathrm{~mm} / \mathrm{sec}$.

ity during this type of swallow preceded suprahyoid function by $25-100 \mathrm{msec}$. In all animals, the activity of the superior head occurred concurrently with that of the masseter and temporal muscles in those swallows associated with mastication (fig. 6).

Pattern B was confirmed by dissection to originate within the superior head of the lateral pterygoid muscle. This head, which is directly contiguous with the articular disc, the joint capsule, and with the condylar head, was not active during opening movements as was the inferior head, but rather had a separate and independent function.

\section{DISCUSSION}

Christensen ('69) has observed that the two heads of the lateral pterygoid muscle in man are distinct anatomical entities.
He states that the origins of the two heads are separate, that the fibers of each head run in entirely different directions, that there is no fusion of the fibers of each entity, and reasons that they must have separate functions. Grant ('73b) notes similar findings in a biomechanical study of the lateral pterygoid in both man and the rhesus monkey. He states that the two heads have quite different orientations and relationships to the instantaneous centers of rotation of the mandible (Grant, '73a). The superior head is biomechanically suited to close the jaws while the inferior head is suited to function in opening movements. Grant states the lateral pterygoid muscle is more efficient mechanically in opening the mandible if only the inferior head is active than if both heads function in this movement.

The results of the current study indicate 
$500 \mu v \bigsqcup_{500 \mathrm{msec}}$

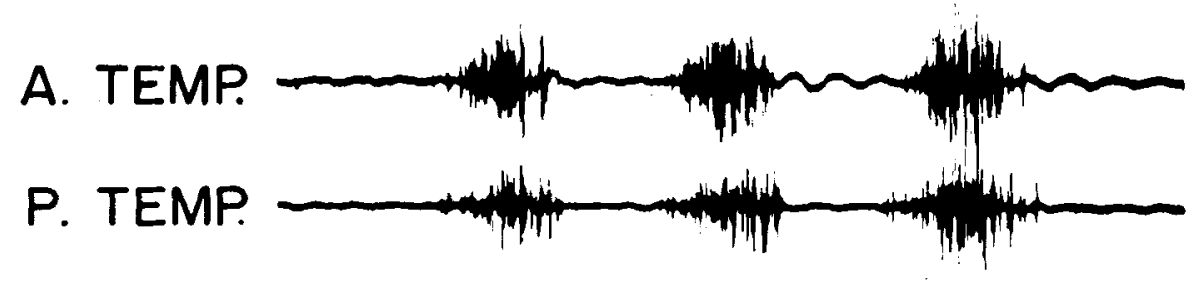

MASS.

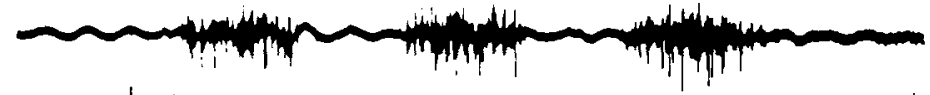

ORBIC. ORIS.

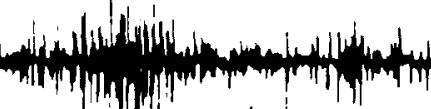

(1)

SUP. HY

LAT. PT. (SUP.)
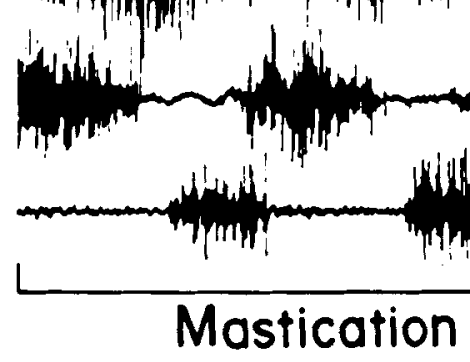

Fig. 6 Electromyographic recordings of the activity of the superior head of the lateral pterygoid muscle during mastication and deglutition. Recording speed $100 \mathrm{~mm} / \mathrm{sec}$.

that the two heads of the lateral pterygoid muscle in Macaca mulatta are functionally independent. The superior head of the lateral pterygoid in the monkey is shown to be the only portion of the muscle electrically active during closing movements while the inferior head with a downward orientation is active during opening movements. The latter head presumably assists translations of the head of the condyle anteriorly, inferiorly, and contralaterally, that is, in movements in which the condylar head is moved freely relative to the articular eminence.

It can be postulated that a slight contraction of the superior head may stabilize the condylar head and articular disc, keeping them synchronized with one another during movement against the articular eminence of the temporal bone, especially dur- ing such functional movements as chewing and swallowing. Sicher ('60) states that the holding force of the lateral pterygoid in man is necessary to prevent the displacement of the mandible during mastication. Perhaps increased contraction of the superior head may move the articular disc, condylar head, and joint capsule anteriorly and slightly superiorly, presumably against the posterior and inferior surface of the articular eminence. Thus, this head may act as a positioner of the condyle and articular disc along the articular surface of the temporal bone.

Previous electromyographic studies in man have not differentiated between the functions of the two heads of the lateral pterygoid muscles. Most investigators have agreed that the lateral pterygoid muscle functions in protrusive and lateral move- 
ments of the mandible (Moyers, '50; Zenker and Zenker, '55; Carlsöö, '56; Woelfel et al., '57, '60; Møller, '66; Griffin and Munro, '69). However, confusion remains as to the role of this muscle in opening and closing movements. Moyers ('50) has suggested that the primary function of the lateral pterygoid is to draw the condylar head and disc forward, but he also suggests that the lateral pterygoid is responsible for the initiation of mandibular depression while the suprahyoid muscles are operative in the completion of the movement. Hickey et al. ('57a) and Woelfel et al. ('60) in contrast found that the lateral pterygoid is active only in "uncontrolled" openings, i.e., with anterior translation of the condyle, but when a hinge opening is performed, the suprahyoids function unassisted. Ekholm and Siirilä ('60) stated that the lateral pterygoid is not essential for opening, but that it is habitually used to place the condyle in a more favorable position.

Activity in the lateral pterygoid during closing movements has not been observed by all investigators. Zenker and Zenker ('55), Carlsöö ('56), Hickey et al. ('57b), Møller ('66), and Griffin and Munro ('69) observed some degree of activity during elevation of the mandible. Moyers (' 50 ), Woelfel et al. ('57, '60), and Ekholm and Siirilä ('60) did not note firing during these movements.

The discrepancy in the above findings is undoubtedly related to the fact that the lateral pterygoid has been considered to be a single functional entity and variations in electrode placement within the separate heads of the muscle have not been considered. As has been found to be the case with other muscles of mastication (e.g., masseter, temporal), ascribing a single primary function to the lateral pterygoid muscle likely misrepresents the total scope of activity of this muscle. In the current study the lateral pterygoid muscle in Macaca mulatta demonstrated several distinct and independent functions: the inferior head participated with the suprahyoid muscle group in opening movements of the mandible, while the superior head was electrically active both in closing movements (e.g., mastication) and in movements with little or no elevator activity (e.g., specific salivary swallows). Thus, a contraction of the superior head may stabilize the condylar head and disc against the articular eminence. In contrast, close approximation of the condylar head and disc to the articular eminence may not be essential in opening movements or even desirable in wide open movements. Further increased contractions of the superior head of the lateral pterygoid, as in more protrusive closure patterns, may help maintain the relationship of the condylar head and disc as the mandibular condyle is positioned or rotated anteriorly along the articular surface of the eminence.

Some care, of course, must be taken in directly relating the findings of the current study of the role of the lateral pterygoid muscle in Macaca mulatta to the role of the same muscle in man, especially considering the anatomical differences between the two species previously described. For both the rhesus monkey and man, further investigations into the nature and orientation of the fibers of each head as well as the innervation and muscle spindle distribution are necessary if a more complete understanding of the roles of the lateral pterygoid muscle is to be attained.

\section{ACKNOWLEDGMENTS}

The author wishes to thank Dr. Takayuki Kuroda, Dr. Daryl Bowden, and Dr. Robert $E$. Moyers for their help in the preparation of this manuscript. The author is also grateful to Dr. Merle Lawrence and Dr. Robert E. Stone of the Kresge Hearing Research Institute for providing the electromyographic facilities used in this study. Illustrations were prepared by Ms. Sally Everhardus, Mr. Gerald G. Davenport, and Mr. Edward E. Sayer.

\section{LITERATURE CITED}

Angel, J. L. 1948 Factors in temporomandibular joint form. Am. J. Anat., 83: 223-246.

Bosma, J. F. 1956 Myology of the pharynx of cat, dog and monkey with interpretation of the mechanism of swallowing. Ann. Oto. Rhino. Laryng., 65: 981-992.

Carlsöö, S. 1952 Nervous coordination and mechanical function of the mandibular elevators. Acta Odont. Scand., 10: 132 pp., Suppl. 11.

- 1956 An electromyographic study of the activity, and an anatomic analysis of the mechanics of the lateral pterygoid muscle. Acta Anat., 26: 339-351. 
Christensen, F. G. 1969 Some anatomical concepts associated with the temporomandibular joint. Ann. Austral. Coll. Dent. Surg., 2: 3960.

Ekholm, A., and H. S. Siirilä 1960 An electromyographic studv of the function of the lateral pterygoid muscle. Suom. Hammaslääk. Toim, 56: $90-106$.

Grant, P. G. 1973a Biomechanical significance of the instantaneous center of rotation: the human temporomandibular joint. J. Biomech., 6: $109-113$.

1973b Lateral pterygoid, two muscles? Am. J. Anat., 138: 1-10.

Griffin, C. J., and R. R. Munro 1969 Electromyography of the jaw-closing muscles in the open-close-clench cycle in man. Archs, oral Biol., 14: 141-149.

Hickey, J. C., J. B. Woelfel and L. Rinear 1957a The influence of overlapping electrical fields on the interpretation of electromyograms. J. Prosth. Dent., 7: 273-281.

Hickey, J. C., R. W. Stacy and L. Rinear 1957b Eleotromyographic studies of mandibular muscles in basic jaw movements. J. Prosth. Dent., 7: 565-570.

Howell, A. B., and W. L. Straus, Jr. 1969 The Anatomy of the Rhesus Monkey, C. G. Hartman and W. L. Straus, Jr., eds. Hafner Publishing Co., New York, Chap. VII, pp. 89-175.

Kuroda, T., and J. A. McNamara, Jr. 1972 The effect of ketamine and phencyclidine on muscle activity in non-human primates. Anesth. Analg., 51: 710-716.

McNamara, J. A., Jr. 1973 Restraint of monkeys for craniofacial research. J. Dent. Res., 52: 183.

McNamara, J. A., Jr., and T. Kuroda 1971 Anesthetic artifacts in electromyographic re- cordings of rhesus monkeys. J. Dent. Res., IADR Suppl. \#485, p. 184.

Møller, E. 1966 The chewing apparatus. An eleotromyographic study of the action of the muscles of mastication and its correlation to facial marphology. Acta Physiol. Scand, Vol. 69, Suppl. 280.

Moyers, R. E. 1950 An electromyographic analysis of certain muscles involved in temporomandibular movement. Am. J. Orthodont, 36: 481-515.

Parsons, F. G. 1899 The joints of mammals compared with those of man. J. Anat. Physiol., 34: 41-68.

Schumacher, G. H. 1961 Funktionelle Morphologie der Kaumuskulatur. Gustav Fischer Verlag, Jiena.

Sicher, H. 1960 Oral Anatomy. Third edition, C. V. Mosby Co., St. Louis, Missouri.

Woelfel, J. B., J. C. Hickey and L. L. Rinear 1957 Electromyographic evidence supporting the mandibular hinge axis theory. J. Prosth. Dent., 7: 361-367.

Woelfel, J. B., J. C. Hickey, R. W. Stacy and L. L. Rinear 1960 Electromyographic analysis of jaw movements. J. Prosth. Dent., 10: 688-697.

Zenker, W, and A. Zenker 1955 Die Tätigkeit der Kiefermuskeln und ihre elektromyographische Analyse. Z. Anat. Entwicklgesch., 119: 174-200.

Zielinski, D. E. 1965 A study of the normal anatomy of the masticatory apparatus of Macaca mulatta. M.S. Thesis, Loyola University Graduate School, Chicago, Illinois.

Zimmermann, H. I. 1971 The normal gnowth and remodeling of the temporomandibular joint of Macaca mulatta. M.S. Thesis, University of Washington, Seattle, Washington. 